\title{
Kommentaar op die artikels van prof Wessel Pienaar rakende riglyne by die keuse van padprojekte deur die Suid-Afrikaanse owerheid
}

\author{
Ewert KLeynhans \\ Skool vir Ekonomie, Noordwes-Universiteit \\ Potchefstroom \\ E-pos: Ewert.Kleynhans@nwu.ac.za
}

Ewert KLeynhans is professor in Ekonomie aan die Noordwes-Universiteit in Potchefstroom en sy navorsing fokus op die mededingendheid van firmas en nywerhede. Hy studeer aan die Normaalkollege Pretoria en verwerf gedurende 1980 'n onderwysdiploma, waarna hy sestien jaar lank skoolhou. Hy verwerf die Verdere Diploma in Wiskunde en Natuurwetenskappe aan die Onderwyskollege vir Verdere Onderwys met lof gedurende 1989, en sy graad aan die Universiteit van Suid-Afrika (UNISA) in 1991. Einde 1993 verwerf hy 'n honneursgraad in Ekonomie en in 1994 sy meestersgraad aan die Randse Afrikaanse Universiteit - beide cum laude. In 1996 word hy aangestel as lektor by die Potchefstroomse Universiteit vir Christelike Hoër Onderwys. In 2003 verwerf hy sy doktorsgraad (PhD) in Ekonomie aan die Potchefstroomse Universiteit en word bevorder tot senior lektor, word medeprofessor by die Noordwes-Universiteit (NWU) gedurende 2007 en volprofessor in 2017. In 2012 behaal hy ook 'n meestersgraad in Filosofie (M.Phil.) aan die NWU. Hy het reeds meer as vyftig artikels in geakkrediteerde vakjoernale gepubliseer en by talle plaaslike en internasionale konferensies opgetree in plekke soos Italië, Spanje, Griekeland, Nederland, Las Vegas, Hawaii, Boston en Washington in die Verenigde State van Amerika. Hy het vyf jaar op die Akademieraad van die Suid-Afrikaanse Akademie vir Wetenskap en Kuns gedien en was jare lank sekretaris van die Potchefstroomse Werksgemeenskap. Sy stokperdjies is tropiese visse, Elektronika, Wiskunde en Filosofie.
EWERT KLEYNHans is professor of Economics at the North-West University in Potchefstroom and his research focuses on the competitiveness of firms and industries. He obtained a teacher's diploma in 1980 from the Normaalkollege Pretoria and became a school teacher for sixteen years. He acquired a Further Diploma in Mathematics and Natural Sciences from the College of Education for Further Training cum laude in 1989, and his degree at the University of South Africa (UNISA) in 1991. In 1993 he was awarded the honours degree in Economics and in 1994 his masters, both cum laude from the Rand Afrikaans University. He was appointed as a lecturer at the Potchefstroom University for Christian Higher Education in 1996. After obtaining his doctorate $(\mathrm{PhD})$ in Economics at the Potchefstroom University during 2003, he was promoted to senior lecturer at North-West University (NWU), became associate professor in 2007 and full professor during 2017. In 2012 he also obtained a Master's degree in Philosophy (MPhil) at the NWU. He has already published more than fifty articles in accredited journals and read papers at conferences locally and internationally at places such as Italy, the Netherlands, Spain, Greece, Las Vegas, Hawaii, Boston and Washington in the United States of America. He served for five years as a board member of the South African Academy of Science and Arts. His hobbies include tropical fish, Electronics, Mathematics and Philosophy. 
Die besteding van belastingbetalers se geld verg altyd 'n omsigtige benadering. Die ekonomiese wetenskap bestudeer die optimale aanwending van beperkte fondse om die meeste te bereik. Wanneer daar dus oor die bou van paaie besin word, is dit noodsaaklik dat die beperkte fondse waaroor die owerheid beskik, sodanig aangewend sal word dat dit die grootste voordeel vir die land en sy mense sal hê. Hulpbronne is altyd beperk en wanneer daar meer belasting van die publiek gevra word, is mense ongelukkig. Die heel beste keuses rakende besteding deur die owerheid op aspekte soos gesondheid, veiligheid of infrastruktuur is daarom noodsaaklik.

Die genoemde artikels is van besondere waarde omdat goeie paaie en ander vervoerinfrastruktuur uiters noodsaaklik is vir die funksionering van die land, die ratte van industrie en die ekonomie. Die swak toestand waarin Suid-Afrikaanse paaie tans verkeer, is alombekend. Daar bestaan talle behoeftes vir die onderhoud en herbou van bestaande paaie en ook vir die bou van nuwe paaie. 'n Land se ekonomiese groei en ontwikkeling is direk afhanklik van die kwaliteit van die land se infrastruktuur (Vigren \& Ljungberg 2018:560; Coetzee \& Kleynhans 2017). In hierdie verband maak Pienaar se twee artikels 'n besondere bydrae.

Die kriteria vir die publikasie van 'n artikel deur'n akademiese vakjoernaal is in die eerste plek dat dit'n noemenswaardige bydrae tot die bestaande ensiklopedie van kennis moet maak. Dit moet gevolglik iets nuuts na die akademiese gemeenskap bring. 'n Publikasie is immers die finale uitkoms van navorsing.

Ander publikasiekriteria mag egter ook die oordra van inligting deur die redakteur of voorsitter van 'n vakvereniging, of die herdenking, besinning of bereiking van 'n besondere mylpaal in 'n instansie of persoon se loopbaan wees.

Die artikels wat oor die kriteria en metodes by die bou van paaie handel, maak 'n bydrae tot akademiese kennis, is van praktiese waarde en is die eindproduk en herdenking van ' $\mathrm{n}$ besondere akademikus, vervoerekonoom, ingenieur en voormalige landswye voorsitter van die Suid-Afrikaanse Akademie vir Wetenskap en Kuns, prof dr Wessel Pienaar. Dit is gevolglik 'n eer vir die Tydskrif vir Geesteswetenskappe om hierdie artikels te mag publiseer. Artikels van hierdie kaliber word gewoonlik eerder in 'n tydskrif vir natuurwetenskappe en/of ingenieurswese gepubliseer, waar dit meer aandag van eweknie-navorsers in die veld kan geniet.

Alhoewel die outeur 'n outoriteit op die gebied van koste-voordeel-analise en vervoerekonomiese analise is, is die artikels egter in 'n formaat geskryf wat dit vir die algemene leser toeganklik maak. Daar mag wel aangevoer word dat die inhoud van die twee artikels grootliks verkort kon word en as 'n enkele artikel gepubliseer kon word. Die skeiding van die algemene beskrywing van die keuseproses en die meer tegniese artikel met berekeninge, was egter waardevol aangesien almal die beskrywende artikel kan lees en verstaan, maar dat die formules, tabelle en wiskundige berekeninge talle lesers mag afskrik. Nou kan die lesers kies wat hulle wil lees sonder om 'n gedeelte van die inhoud van 'n besondere artikel te verloor.

Die probleem met die meeste empiriese analises is dat dit nie moontlik is om uit die artikel na te speur hoe die navorsing presies gedoen is nie. Die metodologie word wel gegee, maar oor die spesifieke metodes en berekening wat gevolg is, is outeurs gewoonlik vaag (Cavill 2008:297). Die meriete van Pienaar se jongste publikasies lê juis daarin dat dit in detail uitspel hoe die ontleding gedoen word. Dit verleen praktiese waarde aan die artikels wat beteken dat dit dikwels in die toekoms in die praktyk gebruik kan word. Sy metodes is ook nie slegs van belang vir padbouprojekte nie, maar kan op'n wye front van investeringsprojekte toegepas word. In hierdie opsig mag die artikels ook in akademiese opleidingsprogramme van waarde wees.

Ter wille van wetenskaplikheid moet 'n outeur alle stellings bewys deur gesaghebbende bronverwysings vir elke stelling te voorsien. Anders as wat algemeen aanvaar kon word, is die voorkoms van talle bronverwysings juis 'n aanduiding van wetenskaplikheid en die navorser 
se kundigheid op die terrein. Vanweë die feit dat die outeur 'n wêreldkenner is, noodsaak dit die outeur om telkens ook na sy eie werke te verwys. In sulke gevalle is dit noodsaaklik, aangesien dit op selfplagiaat sou neerkom indien sodanige verwysings nagelaat sou word. Daar bestaan egter wel talle werke wat soortgelyke onderwerpe navors of selfs teoretiese werke wat dit onderlê. 'n Outeur kan gevolglik maklik na ander navorsers se werk kruisverwys en ook aantoon waar die teorie sy werk ondersteun of daarvan verskil.

Die metode wat die outeur aanbeveel om tussen alternatiewe padbouprojekte te kies, is van besondere belang, omdat dit maklik is om te bereken. Dit is ook maklik vir bestuurders, besluitnemers en politici om te verstaan. Dit benodig min data om die optimale uitkoste te bepaal. Meer gevorderde metodes bestaan wel, maar benodig groot hoeveelhede moeilik bekombare data, en omdat dit moeilik is om te bereken en die resultate te verstaan, word dit dikwels nie gedoen nie, of die resultate word eenvoudig geïgnoreer.

Die artikels spreek twee scenario's aan. Eerstens toon dit aan hoe die owerheid te werk behoort te gaan wanneer 'n bepaalde bedrag in sy begroting aan padbouprojekte toegeken is. Beplanners moet dan bepaal watter padbouprojekte onderneem behoort te word, ten einde die beskikbare fondse optimaal toe te wys. Daar bestaan gewoonlik 'n groot aantal behoeftes aan paaie en daar moet dan tussen verskeie mededingende projekte ten beste gekies word. Die tweede geval is waar daar nog nie 'n begroting bestaan nie en behoeftes bepaal moet word. In sodanige geval moet daar bepaal word watter projekte die belangrikste en/of die grootse dividend gaan oplewer, en vir watter bedrae daar by die owerheid aansoek gedoen moet word.

Eerstens moet in beide gevalle bepaal word wat die voordele van die onderskeie paaie sal wees. Hier word dikwels in Ekonomie van die ceteris paribus-beginsel gebruik gemaak, wat beteken "indien alle ander faktore konstant bly". In die praktyk veronderstel dit dikwels dat daar slegs na die kostes gekyk word, sonder om ander faktore in ag te neem. Dikwels word dinamiese terugspoel-faktore wat volg op die uitkoms van sodanige projekte en die wisselwerking daarvan op alle ander aspekte van die ekonomie buite rekening gelaat.

Dit was ook in Pienaar se twee artikels die geval. Indien 'n pad byvoorbeeld in die rigting van 'n nuwe ontwikkeling soos 'n winkelkompleks gebou sou word, sou vervoer daarheen en ook ander sake in die gebied, goedkoper wees. Dit sal besigheid in die omgewing meer winsgewend maak en ekonomiese ontwikkeling daar bevorder. Ekonomiese onwikkeling van een projek mag ook tot' $n$ wisselwerking aanleiding gee, en ontwikkeling van ander veroorsaak. Meer werkers sal nou in die gebied gaan werk vanweë die nuwe toegangsroete, maar ook as gevolg van die werksgeleenthede wat die nuwe ontwikkelinge skep. Hulle sal nou inkome verdien en ook markvraag in die gebied verhoog. Uiteindelik gaan dit ook 'n welvaartseffek hê en armoede onder landsburgers verlaag. So 'n nuwe pad het gevolglik ook'n sosiale impak; dit mag die vervoertyd tussen huis en werk verminder sodat mense langer tye by hul huisgesinne kan wees en so ook beter opvoeding van ons jeug tot gevolg kan hê. Indien daar egter dikwels diensleweringsbetogings langs die nuwe roete is, mag dit mense se veiligheid bedreig, terwyl 'n korter roete tog ook sal lei tot minder motorongelukke. Dit mag egter ook 'n impak op omgewingsfaktore hê en die koolstofvoetspoor vergroot. Daar is ook nie aandag aan die elastisiteit van substitusie, en die inkome en verspreidingseffekte geskenk nie (Walle 2002:575).

Daar is gevolglik baie aspekte en faktore wat Pienaar se artikels nie in ag neem nie. Talle hiervan is ook nie slegs 'n eenmalige gebeurtenis nie, maar is dikwels besonder dinamies, veranderlik en kompleks. Dit is egter wel ook 'n positiewe punt aangesien te veel faktore die analise van die syfers uiteindelik totaal sou verlam en dit baie ingewikkeld word om te modelleer (Vickerman 2000:16). In hul studie bestudeer Laird en Venables (2017) daarom eerder 'n versameling van faktore wat die voordele en kostes beïnvloed, en nie slegs die onmiddellike 
verbruikersvoordele nie. Hul studie fokus op die voordele aan gebruikers, nabyheid, die effek op produktiwiteit, investering, grondgebruik en indiensname. Daar is egter nie konsensus by navorsers oor hoe omgewings- en sosiale impakte benader behoort te word nie. In meeste gevalle word daar in die rigting van komprehensiewe multimodale benaderings met groter klem op multi-kriteria-analise gewerk (Bristow \& Nellthorp 2000:51). Munger (2000) beweer egter dat koste-voordeel-analise die heel belangrikste enkele probleemoplossingsinstrument is wanneer beleidsake bestudeer word.

Nuwe padbouprojekte lei tot verdere voordele en ontwikkeling in die toekoms, wat nie noodwendig tydens die aanvanklike analise in ag geneem is nie (Pienaar 2005). Dinamiese effekte is byvoorbeeld wanneer daar terugvoer-voordele of -nadele na die oorspronklike voordele en kostes van 'n padbouprojek teruggevoer word en dit die uitkomste weer in 'n ander rigting voer, wat dan weer tot ander ekonomiese veranderinge lei wat dan weer lei tot padbouvoordele wat verander en wat nie aanvanklik voorsien was nie. Kim, Hewings en Amir (2017) het sodanige dinamika in hul finansiële algemene ewewigsanalise ondersoek.

Pienaar $(2014 ; 2016)$ het wel in vroeëre artikels aandag geskenk aan die ekonomiese ontwikkelingsaspekte van padbouprojekte, soos die verlaging van armoede en die bevordering van gelyke inkomeverdeling (Walle 2002:575).

Die metode wat Pienaar (2019) se nuutste artikels voorstel, is basies om eerstens die effek van prysverhogings deur die jare in ag te neem en die kostes en voordele wat'n toekomstige pad mag inhou, met die inflasiekoers te defleer. Inflasie laat bedrae geld groter lyk, terwyl dit nie die geval is nie. Wanneer die effek van inflasie uitgehaal is, maak dit die vergelyking van bedrae van verskillende jare moontlik. Daarna word die voordele wat elke moontlike pad mag inhou, in die jare wat kom, bereken. Die koste van die bou en instandhouding van die pad word dan bepaal en van die voordele afgetrek (Tinbergen 1957:242). Dit laat mens dan met 'n netto bedrag wat die moeite werd mag wees, indien dit positief is.

Daar sal egter talle projekte wees wat winsgewend mag wees, terwyl die vergelyking van groot projekte met kleiner projekte misleidend mag wees. Pienaar se artikels is hier besonder innoverend deurdat dit vergelykende verhoudings van die netto voordele van onderskeie projekte vergelyk en bepaal hoeveel dit verskil, terwyl dit die fondse wat nie gebruik is nie telkens in heroorweging neem om te verseker dat alle fondse bestee is en wel op die mees voordelige wyse.

Daar bestaan talle ander metodes wat hier gebruik kon word. Daar is reeds op die dinamiese en terugspoel-effekte gewys. 'n Verandering op een plek in die ekonomie het altyd'n rimpeleffek regdeur die ekonomie en verander al die ander aspekte van die ekonomie. Hier is die gebruik van algemene ewewigsmodulering besonder waardevol. Liniêre programmering word ook dikwels in operasionele navorsing gebruik om optimale posisies te bepaal, maar soos met die vorige metode is dit omslagtig en uiters ingewikkeld om te gebruik. Talle van die analises in die artikels, soos dié van Tinbergen (1957), en Kim, Hewings en Amir (2017) se formules en berekeninge vertoon so ingewikkeld en moeilik verstaanbaar dat dit die deursnee-navorser sal afskrik.

Dit is nie heeltemal duidelik hoe Pienaar (2019) die voordele van toekomstige padprojekte bepaal nie, en hier is moontlik ruimte vir besluitnemers om partydig te wees (Mouter 2017). Korytárová en Papežíková (2015:736) gebruik Monte Carlo-simulasies om die voordele te bepaal, maar die metode is buite die bereik van meeste analiste. Dieselfde geld ook vir ander metodes wat in die keuse van padbouprojekte gebruik word, soos sensitiwiteitsanalise, scenarioanalise, kwantitatiewe optimisme sydigheid en kwalitatiewe benaderings (Miller \& Szimba 2015:65). 
Daar is wel faktore wat nie in syfers gemeet of gerangskik kan word nie, maar tog wel baie belangrik is by die keuse van projekte. In baie gevalle word sulke faktore dan bloot geïgnoreer (Mackie \& Preston 1998; Mackie, Worsley \& Eliasson 2014:3). Deur'n planmatige en wetenskaplike metodologie te volg, soos Pienaar (2019a) in sy eerste artikel voorstel, kan sodanige faktore wel ondervang en aangespreek word.

In 'n vorige artikel vergelyk Pienaar (2016) ook die gebruik van koste-voordeelanalise met streeksekonomiese inkome-analise, waarin die voordele van eersgenoemde aangedui is. Elke metode het natuurlik unieke gevalle waar dit spesifiek aangewese is. In talle artikels het Pienaar (bv. 2016; 2008; 2005) wel dinamiese aspekte ingebou deur ekonomiese vermenigvuldigers en versnellers te bereken, wat bepaal hoe groot die impak van bepaalde padbouprojekte op die breëre streeksekonomie sal wees. Die metodes is egter nie direk op die huidige artikels van toepassing nie. Reeds met die aanvang van die huidige millennium publiseer Pienaar (2002) riglyne vir die keuse van ekonomiese openbare infrastruktuurprojekte. Hierdie idees het hy gedurende die afgelope twee dekades verfyn en die huidige twee artikels is die uiteindelike produk daarvan in 'n meer gebruikersvriendelike formaat.

Pienaar se artikels het juis in hierdie opsig meriete, aangesien dit leservriendelik geskryf is en ook die meer beskrywende gedeeltes van die meer wiskundige skei. Die metodologie en berekeningsmetodes wat Pienaar in sy artikels aanbeveel, is eenvoudig, beide vir die berekening daarvan, maar ook die interpretasie daarvan deur beleidsmakers, bestuurders en politici, dit gebruik baie min inligting en gaan ekonomies om met die data. Dit maak die artikels besonder bruikbaar en van praktiese waarde. Vanweë hierdie eienskappe van die twee artikels kan daar aangeneem word dat die artikels nog baie in die toekoms gebruik en na verwys gaan word.

\section{BIBLIOGRAFIE}

Bristow, A.L. \& Nellthorp, J. 2000. Transport project appraisal in the European Union. Transport Policy, $7(1): 51-60$.

Cavill, N., Kahlmeier, S., Rutter, H., Racioppi, F. \& Oja, P. 2008. Economic analyses of transport infrastructure and policies including health effects related to cycling and walking: a systematic review. Transport Policy, 15(5):291-304.

Coetzee, C.E. \& Kleynhans, E.P.J. 2017. Public capital stock and economic growth - A KwaZulu-Natal case study. South African Journal of Economic and Managerial Sciences, 20(1): a1591: 1-10. DOI: http://dx.doi.org/10.4102/sajems.v20i1.1591

Kim, E., Hewings, G.J. \& Amir, H. 2017. Economic evaluation of transportation projects: An application of financial computable general equilibrium model. Research in Transportation Economics, 61:44-55.

Korytárová, J. \& Papežíková, P. 2015. Assessment of large-scale projects based on CBA. Procedia Computer Science, 64:736-743.

Laird, J.J. \& Venables, A.J. 2017. Transport investment and economic performance: A framework for project appraisal. Transport Policy, 56:1-11.

Mackie, P., Worsley, T. \& Eliasson, J. 2014. Transport appraisal revisited. Research in Transportation Economics, 47:3-18.

Mackie, P. \& Preston, J. 1998. Twenty-one sources of error and bias in transport project appraisal. Transport Policy, 5(1):1-7.

Miller, M. \& Szimba, E. 2015. How to avoid unrealistic appraisal results? A concept to reflect the occurrence of risk in the appraisal of transport infrastructure projects. Research in Transportation Economics, 49:65-75.

Mouter, N. 2017. Dutch politicians' attitudes towards cost-benefit Analysis. Transport Policy, 54:1-10.

Munger, M. 2000. Analyzing policy: choices, conflicts and practices. New York: W.W. Norton.

Pienaar, W.J. 2002. Riglyne vir die keuse van ekonomiese openbare infrastruktuurprojekte: research and review article. Suid-Afrikaanse Tydskrif vir Natuurwetenskap en Tegnologie, 21(2):47-55. 
Pienaar, W.J. 2005. Die beraming van verhoogde streeksinkome wat uit ekonomies geregverdigde padbouprojekte spruit. Suid-Afrikaanse Tydskrif vir Natuurwetenskap en Tegnologie, 24(4):108-117.

Pienaar, W.J. 2008. Economic evaluation of the proposed road between Gobabis and Grootfontein, Namibia. South African Journal of Economics, 76(4):667-684.

Pienaar, W. 2014. Die uitbreiding van kostevoordeelontleding met sosiale evaluering in die beplanning van openbare padbouprojekte: voorstel ter ondersteuning van die skep van 'n ontwikkelingstaat. Tydskrif vir Geesteswetenskappe, 54(4):753-770.

Pienaar, W.J. 2016. Regional economic assessment of the planned De Beers Pass Road project in South Africa. South African Journal of Industrial Engineering, 27(4):182-192.

Pienaar, W.J. 2019a. Riglyne by die keuse van padprojekte deur die owerheid. Tydskrif vir Geesteswetenskappe. 59(1):126-141.

Pienaar, W.J. 2019b. Voorgestelde metodes om die voordele van padbouprojekte te maksimeer. Tydskrif vir Geesteswetenskappe. 59(1):142-156.

Tinbergen, J. 1957. The appraisal of road construction: two calculation schemes. Review of Economics and Statistics, pp. 241-249.

Vickerman, R. 2000. Evaluation methodologies for transport projects in the United Kingdom. Transport Policy, 7(1):7-16.

Vigren, A. \& Ljungberg, A. 2018. Public transport authorities' use of cost-benefit analysis in practice. Research in Transportation Economics, 69:560-567.

Walle, D.V.D. 2002. Choosing rural road investments to help reduce poverty. World Development, 30(4):575-589. 